\title{
ANALISIS EFEKTIVITAS TERMINAL ADIWERNA DI KABUPATEN TEGAL
}

\author{
Dimas Anugrah Dwi Saputra ${ }^{1}$ dan Rezza Pamalis ${ }^{2}$
}

\begin{abstract}
The Adiwerna Terminal is a type C terminal located in Tegal Regency which serves passengers and city and rural transportation. In its management, the Adiwerna terminal has not gone well. Problems were found such as the absence of urban and rural transportation entering the terminal, terminal facilities that were not maintained, limited human resources, and services that were not optimal. This makes the writer interested in conducting research on the effectiveness of the Adiwerna terminal in Tegal Regency. This study used a qualitative descriptive study with the location of the research in the Adiwerna terminal. Data collected from interviews, records, until data from print and electronic media were collected into one to draw conclusions that more sharply illustrate the results of observations. As a result, the effectiveness of the Adiwerna terminal in Tegal Regency has not been optimal. In terms of time and cost it is not yet efficient. Service procedures are only regulated with 1 (one) regulation and do not have SOPS. Coordination between superiors and subordinates went well but still did not show high employee responsiveness. The availability of infrastructure is adequate but not well maintained so that passengers cannot use the facilities to the full. Things that are driving factors for the effectiveness of the Adiwerna terminal are 1) Planning Activities, 2) Organizing, 3) Control, 4) Direction, and 5) Decision Making. While the inhibiting factors of effectiveness found in the Adiwerna terminal are 1) Placement, 2) Motivation, and 3) Communication.
\end{abstract}

Keywords: Effectiveness, Management.

\section{PENDAHULUAN}

Kabupaten Tegal merupakan wilayah dengan luas wilayah $876,1 \mathrm{~km}^{2}$ dan jumlah penduduk mencapai 1.429.386 penduduk. Dengan kondisi demikian, mobilitas masyarakat Kabupaten Tegal sangat tinggi hingga membutuhkan sarana prasarana yang memadai. Kabupaten Tegal memiliki dua terminal yang menjadi pusat aktivitas kendaraan umum seperti bus dan angkutan umum yaitu Terminal Dukuhsalam dan Terminal Adiwerna.

Aktivitas terminal Dukuhsalam masih aktif dari kegiatan menurunkan dan menaikkan penumpang orang maupun barang, sedangkan terminal Adiwerna sudah sejak lima tahun terakhir tidak aktif dari kegiatan menurunkan dan menaikkan penumpang.

\footnotetext{
${ }^{1}$ Mahasiswa Prodi S2 Magister Ilmu Administrasi, Departemen Adm Publik, Universitas Diponegoro.

${ }^{2}$ Mahasiswa Prodi S2 Magister Ilmu Administrasi, Departemen Adm Publik, Universitas Diponegoro.
} 
Terminal Adiwerna merupakan terminal yang difungsikan sebagai terminal kelas tipe $\mathrm{C}$, yaitu berfungsi melayani kendaraan penumpang umum untuk angkutan kota $(\mathrm{AK})$ dan angkutan pedesaan (ADES). Keberadaan terminal Adiwerna saat ini sangat memprihatinkan karena sudah sejak lima tahun terakhir tidak ada kegiatan pelayanan di terminal Adiwerna.

Saat ini kawasan terminal Adiwerna terlihat sangat sepi dan tidak terawat. Calon penumpang enggan untuk memanfaatkan terminal sehingga angkutan kota dan angkutan pedesaan tidak lagi masuk ke kawasan terminal Adiwerna. Sopir angkutan kota dan angkutan pedesaan lebih banyak menaikan dan menurunkan penumpang diluar terminal Adiwerna. Kios-kios yang ada di terminal Adiwerna sebagian besar tutup dan hanya satu atau dua yang terbuka kiosnya. Kondisi yang sepi dimanfaatkan oleh beberapa awak bus untuk memarkirkan busnya di terminal Adiwerna. Selain itu, hanya beberapa petugas yang berjaga pada pagi dan siang hari. Kondisi terminal Adiwerna saat ini tidak mencerminkan sebuah terminal pada umumnya. Hal ini menimbulkan pertanyaan bagi penulis mengenai analisis efektivitas terminal Adiwerna serta faktor pendorong dan penghambat dalam pengelolaan terminal Adiwerna di Kabupaten Tegal sehingga keberadaan terminal Adiwerna menjadi kurang optimal.

Efektivitas sebagai pemanfaatan sumber daya, sarana dan prasarana dalam jumlah tertentu yang secara sadar ditetapkan sebelumnya untuk menghasilkan sejumlah barang atas jasa kegiatan yang dijalankannya. Tingkat efektivitas dapat diukur dengan membandingkan antara rencana atau target yang telah ditentukan dengan hasil yang akan dicapai maka usaha atau hasil pekerjaan tersebut.

Untuk mengukur efektivitas terminal Adiwerna, penulis menggunakan pendekatanpendekatan, yaitu:

1. Pendekatan Sumber

Pendekatan ini mengukur efektivitas dari input. Pendekatan ini mengutamakan adanya keberhasilan organisasi untuk memperoleh sumber daya baik fisik maupun non fisik yang sesuai dengan kebutuhan organisasi.

2. Pendekatan Proses

Pendekatan ini untuk melihat sejauh mana efektivitas pelaksanaan program dari semua kegiatan proses interval atau mekanisme organisasi. Pendekatan proses mengukur efektivitas dengan efisiensi dan kondisi kesehatan dari suatu lembaga 
internal diantaranya efisiensi (waktu dan biaya), prosedur pelayanan, koordinasi antara atasan dan bawahan, responsivitas pegawai, dan sarana prasarana

3. Pendekatan Sasaran

Pendekatan sasaran dimana pusat perhatian pada output, mengukur keberhasilan organisasi untuk mencapai hasil (output) yang sesuai dengan rencana. Pendekatan ini mencoba mengukur sejauh mana suatu lembaga berhasil merealisasikan sasaran yang hendak dicapai.

Faktor pendorong dan penghambat diidentifikasi dari kegiatan pengelolaan. Pengelolaan umumnya dikaitkan dengan aktivitas perencanaan, pengorganisasian, pengendalian, penempatan, pengarahan, pemotivasian, komunikasi, dan pengambilan keputusan yang dilakukan oleh setiap organisasi dengan tujuan untuk mengkoordinasikan berbagai sumber daya yang dimiliki oleh organisasi sehingga akan dihasilkan suatu produk atau jasa secara efisien. Sehingga pengelolaan umumnya dikaitkan dengan 1) Aktivitas Perencanaan, 2) Pengorganisasian, 3) Pengendalian, 4) Penempatan, 5) Pengarahan, 6) Pemotivasian, 7) Komunikasi, dan 8) Pengambilan Keputusan.

Penelitian ini dilakukan dengan pendekatan deskriptif kualitatif yang mendeskripsikan serta mengkaji lebih dalam efektivitas pengelolaan terminal Adiwerna. Penulis dalam penelitian lebih bersifat eksploratif dimana setiap kasus memiliki keunikannya sendiri. Lokasi penelitian adalah Terminal Adiwerna Kabupaten Tegal.

Teknik pengumpulan data untuk mengungkapkan permasalahan pada penelitian ini meliputi wawancara, analisis data sekunder, penelusuran berita melalui media cetak maupun elektronik terhadap topik yang dianggap relevan dengan topik yang diambil dalam penelitian ini. Data yang diperoleh kemudian dipilih hal-hal pokok yang sesuai dengan fokus penelitian sehingga didapat gambaran yang lebih tajam mengenai hasil pengamatan. Pada akhirnya data yang diperoleh ditarik kesimpulannya dan diverifikasi baik dari segi makna maupun dari segi kebenaran kesimpulan tersebut.

\section{PEMBAHASAN}

Dalam pembahasan mengenai efektivitas terminal Adiwerna di Kabupaten Tegal, penulis melakukan pembahasan dan analisa berdasarkan indikator-indikator dibawah ini: 


\section{Efisiensi (waktu dan biaya)}

Pelaksanaan pelayanan di terminal Adiwerna pada tahun awal dilakukan setiap hari, seperti dalam pelayanan retribusi. Retribusi pada terminal Adiwerna berupa retribusi penumpang masuk terminal, angkutan kota dan desa masuk, penggunaan MCK, penggunaan kios, dan sebagainya. Namun saat ini pelayanan retribusi tidak berjalan karena tidak ada aktivitas angkutan kota dan desa yang masuk, sehingga penumpang juga tidak memanfaatkan fasilitas terminal. Saat ini yang masih dilakukan yaitu penarikan retribusi pada pengguna kios. Selain tidak adanya aktivitas angkutan kota dan desa masuk terminal Adiwerna, pelayanan retribusi tidak berjalan karena ketersediaan SDM yang terbatas.

Penganggaran dalam pengelolaan terminal Adiwerna berasal dari APBD Kabupaten Tegal. Anggaran digunakan untuk pengelolaan fasilitas di dalam terminal Adiwerna dan juga untuk kegiatan operasional.

\section{Prosedur Pelayanan}

Prosedur pelayanan yang ada dalam pengelolaan terminal Adiwerna diatur dalam Peraturan Daerah Kabupaten Tegal Nomor 3 Tahun 2014 tentang Perubahan Atas Peraturan Daerah Kabupaten Tegal Nomor 2 Tahun 2012 tentang Retribusi Daerah. Perda inilah yang menjadi pegangan petugas terminal Adiwerna untuk melakukan pemungutan sebagai imbalan atas pelayanan penggunaan seluruh failitas yang berada di terminal Adiwerna. Selain itu, di terminal Adiwerna tidak diterapkan SOP pelayanan dalam pengelolaan. Petugas hanya melalukan secara spontan kegiatan di terminal Adiwerna.

\section{Koordinasi Atasan dan Bawahan}

Adanya koordinasi antara atasan dan bawahan ditujukan agar pelaksanaan pengelolaan terminal Adiwerna berjalan dengan lancar dan maksimal. Diketahui bahwa koordinasi atasan dan bawahan hanya sebatas koordinasi kondisi yang ada pada lapangan, permasalahan yang ditemui, informasi-informasi terbaru lainnya hingga pelaporan kinerja terminal Adiwerna. Selain itu, ada koordinasi dan sinergitas yang dilakukan oleh Kepala UPTD Pengelolaan Terminal dengan Kepala Dinas Perhubungan, begitu juga sebaliknya. Dimana tupoksi Dinas Pehubungan Kabupaten Tegal dalam melakukan pembinaan dan penganggaran kebutuhan terhadap operasional terminal Adiwerna. Sedangkan UPTD Pengelolaan Terminal sebagai 
pelaksana teknis dalam melakukan pengelolaan terminal, termasuk terminal Adiwerna.

\section{Responsivitas Pegawai}

Responsivitas adalah daya tanggap pegawai dalam menghadapi hambatan dalam suatu pekerjaan agar pekerjaan tersebut dapat berjalan dengan lancar dan maksimal. Adapun responsvitas pegawai dalam mengatasi hambatan pengelolaan terminal Adiwerna kurang optimal. Banyak masyarakat dan sopir angkutan umum yang mengeluhkan tentang lokasi terminal Adiwerna yang kurang strategis. Daerah terminal Adiwerna tidak banyak dilewati oleh angkutan kota maupun angkutan desa. Sehingga terminal menjadi terlihat sepi dan tidak aktivitas. Angkutan kota maupun pedesaan pun enggan masuk terminal karena kondisi yang sepi penumpang. Pegawai tidak melaksanakan tugas pengawasan terhadap angkutan tersebut untuk masuk ke terminal. Hal ini membuat responsivitas pegawai kurang optimal sehingga belum mampu mewujudkan tercapainya efektivitas dalam pengelolaan terminal Adiwerna.

\section{Sarana Prasarana}

Keberadaan sarana prasarana di terminal Adiwerna ditujukan untuk menunjang proses pengelolaan yang dilakukan oleh petugas terminal Adiwerna. Fasilitas yang ada di terminal Adiwerna sebenarnya sudah memadai sesuai dengan ketentuan fasilitas untuk terminal bertipe C. Fasilitas tersebut seperti MCK, ruang tunggu penumpang, kios-kios pedagang, musala, dan kantor cabang UPTD Terminal Adiwerna. Namun sebagian besar fasilitas yang ada di terminal Adiwerna tidak terpelihara seperti ruang tunggu penumpang yang sekarang menjadi tempat parkir kendaraan roda dua, musala yang atapnya sudah berlubang dan tidak dibersihkan, MCK yang kotor tanpa perawatan, dan kios-kios pedagang hanya sebagian kecil yang dimanfaatkan. Di dalam terminal Adiwerna juga tidak ditemukan tempat sampah umum. Selain itu tidak ada papan pengumuman. Sehingga dapat disimpulkan bahwa sarana prasarana di terminal Adiwerna tidak dalam kondisi yang optimal karena tidak adanya perawatan sarana prasarana.

\section{Faktor Pendorong Dan Penghambat Pengelolaan Terminal Adiwerna, Sebagai}

\section{Berikut:}

1. Faktor Pendorong 
a. Aktivitas Perencanaan, adanya dukungan dari para stakeholders yaitu Pemkab Tegal dan Dinas Perhubungan dalam melaksanakan pembangunan terminal Adiwerna.

b. Pengorganisasian, segala bentuk tugas pokok dan fungsi telah terdokumentasi dalam rencana kerja Dinas Perhubungan Kabupaten Tegal.

c. Pengendalian, adanya pengawasan yang dilakukan Dinas Perhubungan terhadap UPTD Terminal Adiwerna baik secara langsung maupun secara tidak langsung yang berupa laporan-laporan.

d. Pengarahan, ada kejelasan mengenai tupoksi yang menjadikan kegiatan operasional terminal Adiwerna semakin mudah. Pelaksanaan kinerja berdasarkan tupoksi yang telah ditetapkan.

e. Pengambilan Keputusan, Dinas Perhubungan Kabupaten Tegal mempunyai kewenangan penuh dalam pengelolaan terminal Adiwerna, sehingga kegiatan selalu dilaksanakan baik oleh Dinas Perhubungan maupun oleh UPTD Terminal Adiwerna.

2. Faktor Penghambat

a. Penempatan, pegawai UPTD Terminal Adiwerna hanya sebagai pelaksana kegiatan sehingga tidak banyak terlibat dalam kesepakatan maupun dalam pengambilan keputusan.

b. Pemotivasian, masih kurangnya motivasi yang diberikan atasan, selain itu sering ditemui kantor UPTD Terminal Adiwerna yang kosong tanpa petugas. Tidak ada sistem reward dan punishment, semuanya berjalan sesuai tupoksi yang ada.

c. Komunikasi, sebagian besar petugas hanya sebatas menjalankan kewajiban pelaporan atas rencana kerja, sehingga komunikasi yang terjadi hanya satu arah.

\section{PENUTUP}

\section{Simpulan}

Efektivitas terminal Adiwerna dapat dilihat dari:

1) Efisiensi (waktu dan biaya). Pelaksanaan pelayanan retribusi tidak berjalan karena tidak ada aktivitas angkutan kota dan desa yang masuk, sehingga penumpang juga tidak memanfaatkan fasilitas terminal. Saat ini yang masih dilakukan yaitu penarikan retribusi pada pengguna kios. Selain itu, ketersediaan SDM yang terbatas menjadi hambatan pelaksanaan pelayanan dalam terminal Adiwerna. 
2) Prosedur Pelayanan. Prosedur pelayanan yang ada dalam pengelolaan terminal Adiwerna hanya diatur dalam Peraturan Daerah Kabupaten Tegal Nomor 3 Tahun 2014 tentang Perubahan Atas Peraturan Daerah Kabupaten Tegal Nomor 2 Tahun 2012 tentang Retribusi Daerah. Selain itu, tidak ada SOP pelayanan di terminal Adiwerna.

3) Koordinasi Atasan dan Bawahan. Diketahui bahwa koordinasi atasan dan bawahan hanya sebatas koordinasi kondisi yang ada pada lapangan, permasalahan yang ditemui, informasi-informasi terbaru lainnya hingga pelaporan kinerja terminal Adiwerna. Selain itu, ada koordinasi dan sinergitas yang dilakukan oleh Kepala UPTD Pengelolaan Terminal dengan Kepala Dinas Perhubungan, begitu juga sebaliknya.

4) Responsivitas Pegawai. Masih belum optimalnya responsivitas pegawai dalam mengatasi hambatan. Pegawai juga tidak melaksanakan tugas pengawasan terhadap angkutan yang tidak masuk ke terminal.

5) Sarana Prasarana. Sebagian besar fasilitas yang ada di terminal Adiwerna tidak terpelihara seperti ruang tunggu penumpang, musala, MCK, dan kios-kios pedagang. Di dalam terminal Adiwerna juga tidak ditemukan tempat sampah umum dan papan pengumuman.

Hal yang manjadi faktor pendorong efektivitas terminal Adiwerna adalah 1) Aktivitas Perencanaan, 2) Pengorganisasian, 3) Pengendalian, 4) Pengarahan, dan 5) Pengambilan Keputusan. Sedangkan faktor penghambat efektivitas yang ditemukan di terminal Adiwerna adalah 1) Penempatan, 2) Pemotivasian, dan 3) Komunikasi.

\section{Rekomendasi}

Dalam upaya menciptakan efektivitas terminal Adiwerna Kabupaten Tegal maka penulis memberikan rekomendasi sebagai berikut:

1) Optimalisasi trayek angkutan kota dan pedesaan ke terminal Adiwerna;

2) Pembuatan SOP pelayan di lingkungan terminal Adiwerna;

3) Stakeholders melakukan pemantauan dan kunjungan dalam rangka meninjau kegiatan operasional terminal Adiwerna;

4) Meningkatkan kompetensi dan etos kerja pegawai di lingkungan UPTD Pengelolaan Terminal;

5) Memperbaiki sarana dan prasarana yang rusak di lingkungan terminal Adiwerna. 


\section{DAFTAR PUSTAKA}

Martani dan Lubis, 1987. Teori Organisasi. Bandung: Ghalia Indonesia.

Nazir, M. 2003. Metode Penelitian. Jakarta: PT. Ghalia Indonesia.

Siagian, P. Sondang. 2001. Manajemen Sumber Daya Manusia. Jakarta: Bumi Aksara.

Sobri, dkk. 2009. Pengelolaan Pendidikan. Yogyakarta: Multi Pressindo.

Prastya, Danang Eko. Efektivitas Pengelolaan Terminal Kertonegoro di Kabupaten Ngawi (Studi Kasus: Unit Pelaksana Teknis Dinas (UPTD) Terminal Kertonegoro Dinas Perhubungan Komunikasi dan Informatika Kabupaten Ngawi). Jurusan Ilmu Pemerintahan Fakultas Ilmu Sosial dan Ilmu Politik Universitas Muhammadiyah Yogyakarta.

https://www.suaramerdeka.com/news/baca/134163/dishub-akan-tata-pedagang-barangbekas-di-terminal-adiwerna (diakses pada 29/10/2018 pukul 21:37)

http://radarsemarang.com/2016/01/25/terminal-mangkrak-akan-diaktifkan/_diakses pada 29/10/2018 pukul 22:09)

http://organda.or.id/kadishub-slawi-siapkan-sembilan-jalur-trayek/ (diakses pada 29/10/2018 pukul 22:16)

https://infotegal.com/2016/05/banjaran-kota-kecil-yang-kini-makin-semrawut/ (diakses pada 29/10/2018 pukul 22:23)

http://jateng.tribunnews.com/2016/08/10/pkl-banjaran-keluhkan-kondisi-relokasi-diterminal-adiwerna/ (diakses pada 29/10/2018 pukul 22:30) 